\title{
Publisher Correction: The loosening of American culture over 200 years is associated with a creativity-order trade-off
}

Joshua Conrad Jackson (D), Michele Gelfand (D), Soham De and Amber Fox

Correction to: Nature Human Behaviour https://doi.org/10.1038/s41562-018-0516-z, published online 28 January 2019.

In the version of this article initially published, errors appeared in three sentences. In the abstract, the sentence beginning "We next examine" should have read "adolescent pregnancies, crime, and high school attendance"; in the main text, the sentence beginning "More recently, the 1964 Civil Rights Act" should have read "directly challenged the authority of the government" and the sentence beginning "Notably, cultural tightness" should have read "cultural tightness positively correlated with crime". The errors have been corrected in the HTML and PDF versions of the article. 